\title{
The Reverse-Flow Facial Artery Buccinator Flap for Skull Base Reconstruction: Key Anatomical and Technical Considerations
}

\author{
Zainab Farzal $^{1}$ Ana M. Lemos-Rodriguez ${ }^{1}$ Rounak B. Rawal ${ }^{1}$ Lewis J. Overton ${ }^{1}$ Satyan B. Sreenath ${ }^{1}$ \\ Mihir R. Patel ${ }^{2}$ Adam M. Zanation ${ }^{1,3}$
}

${ }^{1}$ Department of Otolaryngology-Head and Neck Surgery, University of North Carolina at Chapel Hill, North Carolina, United States

2 Department of Otolaryngology, Emory University, Winship Cancer Institute, Atlanta, Georgia, United States

${ }^{3}$ Department of Neurosurgery, University of North Carolina at Chapel Hill, Chapel Hill, North Carolina, United States

J Neurol Surg B 2015;76:432-439.

\begin{abstract}
Address for correspondence Adam M. Zanation, MD, Department of Otolaryngology-Head and Neck Surgery, University of North Carolina at Chapel Hill, 170 Manning Drive, CB \#7070, Physician's Office Building Room G-190, Chapel Hill, NC, 27599, United States (e-mail: adam_zanation@med.unc.edu).
\end{abstract}

\begin{abstract}
Keywords

- skull base reconstruction

- facial artery buccinator flap

- cerebrospinal fluid leak

- facial artery

Objective To highlight key anatomical and technical considerations for facial artery identification, and harvest and transposition of the facial artery buccinator (FAB) flap to facilitate its future use in anterior skull base reconstruction. Only a few studies have evaluated the reverse-flow FAB flap for skull base defects.

Design Eight FAB flaps were raised in four cadaveric heads and divided into thirds; the facial artery's course at the superior and inferior borders of the flap was measured noting in which incisional third of the flap it laid. The flap's reach to the anterior cranial fossa, sella turcica, clival recess, and contralateral cribriform plate were studied. A clinical case and operative video are also presented.

Results The facial artery had a near vertical course and stayed with the middle ( $5 / 8)$ or posterior third $(3 / 8)$ of the flap in the inferior and superior incisions. Seven of eight flaps covered the sellar/planar regions. Only four of eight flaps covered the contralateral cribriform region. Lastly, none reached the middle third of the clivus.

Conclusions The FAB flap requires an understanding of the facial artery's course, generally seen in the middle third of the flap, and is an appropriate alternative for sellar/ planar and ipsilateral cribriform defects.
\end{abstract}

\section{Introduction}

With new innovations and evolving technology, the field of skull base surgery has experienced a renaissance in recent decades. Accompanying new elaborate surgical techniques is the ongoing pursuit for optimal means of skull base reconstruction. Whether they arise from cerebrospinal fluid (CSF) leaks, tumor invasion, or radionecrosis, skull base defects must be addressed to restore the necessary physiologic barrier and thus minimize morbidity and mortality among patients undergoing minimally invasive endoscopic skull base surgery. Although the pedicled nasoseptal flap (NSF) has become the workhorse for skull base reconstruction with high success

received

December 23, 2014

accepted after revision

March 8, 2015

published online

June 1, 2015

rates and excellent coverage, it requires preoperative planning to ensure its vascular supply is not disrupted and can only be utilized if the septum has not been invaded by adjacent tumors. ${ }^{1}$ As a result, alternative means of coverage are sought.

Since it was first described in 1992, the pedicled facial artery buccinator (FAB) flap, also reported in the literature as the facial artery myomucosal (FAMM) flap, has been utilized successfully for reconstruction of defects in the floor of the mouth, tongue base, oropharynx, lip, palate, nasal septum, and orbit. ${ }^{2-10}$ Centered on the facial artery, it can be superiorly or inferiorly based with retrograde or anterograde flow, respectively, depending on the location of the defect. ${ }^{11}$ of note, the FAB flap should not be confused with the posteriorly

(c) 2015 Georg Thieme Verlag KC Stuttgart · New York
DOI http://dx.doi.org/ 10.1055/s-0035-1551669. ISSN 2193-6331. 
based buccinator flap that is based on the buccal artery, a branch of the internal maxillary artery. ${ }^{9,10}$ Its advantages include the lack of external facial incisions, long axis of rotation, radioresistance, and minor donor site morbidity. ${ }^{4,5,11-13}$ Additionally, the surgeon has the freedom to harvest the flap following resection of skull base lesions and tailor it precisely to the defect.

Only two cadaveric studies have highlighted the potential of a superiorly based reverse-flow FAB flap as an alternative flap for skull base reconstruction. ${ }^{12,13}$ Rivera-Serrano et al demonstrated the flap can reliably reach the anterior skull base and the planum sphenoidale. ${ }^{12}$ Xie et al explored two possible extensions of the flap including masseteric fascia and mandibular periosteum obtaining an average increase of $2.67 \mathrm{~cm}$ in length and $5.16 \mathrm{~cm}^{2}$ in surface area. ${ }^{13}$ However, only the extension with mandibular periosteum was a feasible option because the risk of facial nerve injury with masseteric fascia harvest was too high. ${ }^{13}$ In light of recent exploration of the flap for skull base reconstruction, our goal was to highlight key technical and anatomical considerations for facial artery identification and the harvest and transposition of the FAB flap to mend the gap between cadaveric analysis and real-life application.

\section{Methods}

We performed a cadaveric feasibility study of the FAB flap at the North Carolina Eye Bank Multidisciplinary Surgical Skills Laboratory at the University of North Carolina at Chapel Hill. Eight superiorly based FAB flaps were raised in four lightly fixed, latex-injected cadaveric heads. These were transposed via Caldwell-Luc and medial maxillectomy approaches using 0 - and 45-degree rigid rod-lens endoscopes (Stryker, Kalamazoo, Michigan, United States) connected to a LED light source via a fiberoptic cable and a high-definition endoscopic camera (Stryker). The flaps were divided into thirds, and the course of the facial artery at the superior and inferior borders of the flap was measured noting in which incisional third of the flap it laid. Flap length and area were measured with flexible surgical rulers (Kendall, Covidien, Mansfield, Massachusetts, United States). The flap's ability to cover defects of the anterior cranial fossa, sella turcica, clival recess, and contralateral cribriform plate were studied. Additionally, we report a successful skull base reconstruction using the FAB flap in an elderly patient with a history of invasive sinonasal mucosal melanoma at the University of North Carolina hospitals. An operative video demonstration of the FAB flap harvest and transposition is also presented (-Video 1) (available in the online version).

\section{Video 1}

Operative video demonstration of facial artery buccinator flap harvest and transposition to anterior skull base defect. Online content including video sequences viewable at: https://www.thieme-connect.com/products/ ejournals/html/10.1055/s-0035-1551669

\section{Clinical Case}

\section{History and Presentation}

A 68-year-old woman with a history of fatigue, left-sided nasal obstruction, nosebleeds, and left eye ophthalmoplegia for several months was referred to our clinic. Sinus computed tomography revealed a large left sinus mass centered within the left ethmoid air cells eroding into the left orbit with displacement of the medial rectus muscle and left optic nerve laterally ( - Fig. 1a). Additionally, she had osseous destruction of the lamina papyracea, cribriform plate, medial wall of the left maxillary sinus, and the nasal septum (-Fig. 1b). Nasal endoscopy with biopsy revealed sinonasal melanoma staged as T4bNOM0 with dural invasion. The patient underwent neoadjuvant chemotherapy prior to a left craniofacial resection, orbital exenteration, left maxillectomy, left subfrontal craniotomy, and resection of involved dura. A pericranial flap was used for skull base reconstruction, and a rectus abdominis muscle flap was used to cover her left orbital maxillary defect. She had no complaints postoperatively and completed $70 \mathrm{mGy}$ of radiotherapy. Seventeen months after radiation completion and 20 months following surgery, she was found to have brain and pulmonary metastases after presenting for altered mental status. While undergoing palliative chemoradiation for metastatic disease, she developed radionecrosis of the skull base with persistent recurrent CSF leak and encephalocele (-Fig. 2). With limited tissue options, it was determined that a FAB flap would be used to cover the defect.

\section{Intraoperative Technique with Operative Video}

Once under general anesthesia, the patient was orotracheally intubated. First, nasal endoscopy was performed using a 0-degree endoscope (Stryker), and the skull base leak was visualized. The area of the leak was addressed with bipolar electrocautery to allow retraction of the encephalocele into the defect. Attention was then turned to the harvest of the FAB flap. The parotid duct was located and the flap was drawn out along buccal mucosa ensuring the duct was not included in the flap. Its size was approximated and extended from the level of the second molar along the gingivobuccal sulcus posteriorly to $1 \mathrm{~cm}$ from the oral commissure anteriorly. The flap was then dissected free using blunt dissection and Bovie electrocautery. Once the flap was elevated, the facial artery was identified, ligated, and clipped. The facial vein was also identified and was not incorporated into the flap. Next, a CaldwellLuc antrostomy was performed to transpose the flap to the patient's defect. The flap was then lengthened and elongated to provide full $100 \%$ coverage.

The grafting site was then prepared. Bipolar electrocautery was used to peel off previously placed AlloDerm that had a central aspect leaking CSF. Mucosa was moved back and cleaned allowing for some bleeding for healthy tissue. The graft was then placed followed by Surgicel (Ethicon, Inc., Somerville, New Jersey, United States) and DuraSeal (Confluent Surgical, Inc., Waltham, Massachusetts, United States) applied around it. NasoPore (Stryker) and Merocel 

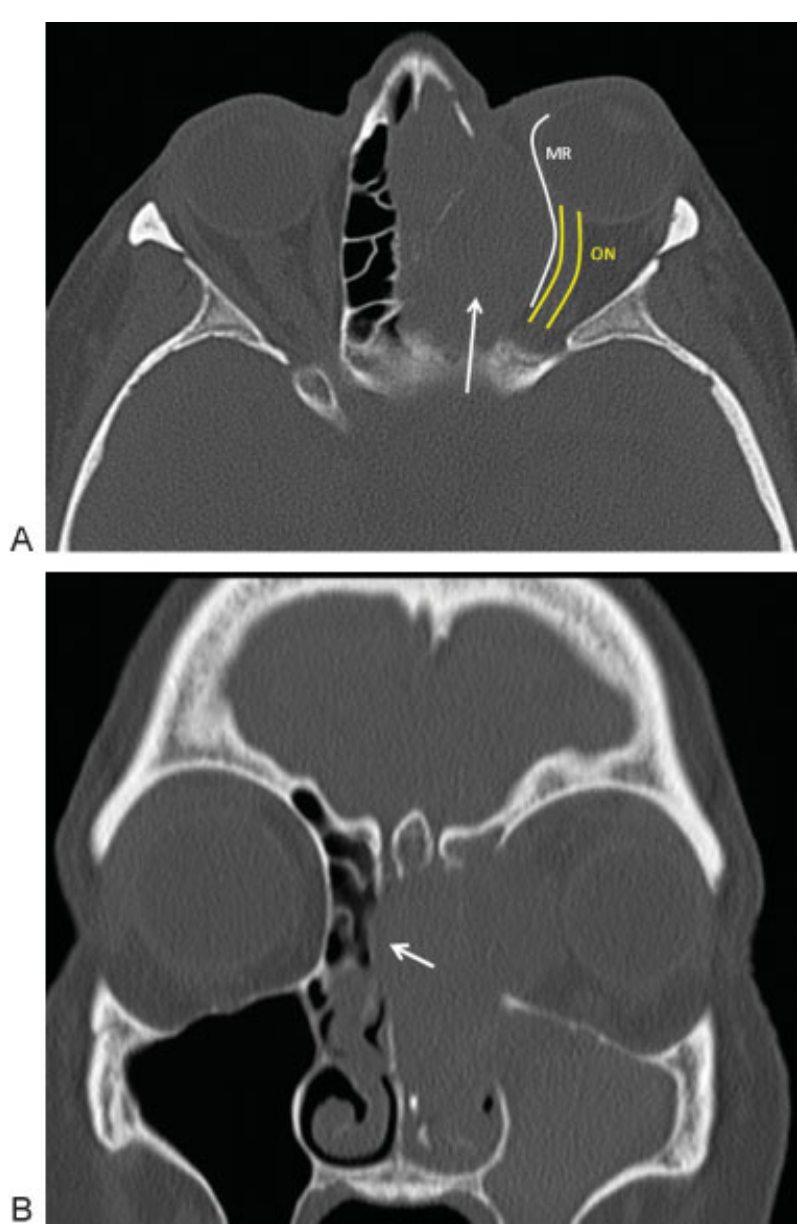

Fig. 1 (A) Sinus computed tomography (CT) visualizing the large mass (white arrow) centered within the left ethmoid sinuses invading the left orbit to displace the medial rectus muscle (MR) and the optic nerve (ON) laterally. (B) Sinus CT with mass involving the left nasal cavity and left maxillary sinus with adjacent destruction of the lamina papyracea, medial wall of the left maxillary sinus, cribriform plate, ethmoid roof, and nasal septum. It crossed midline to involve the right nasal cavity (white arrow).

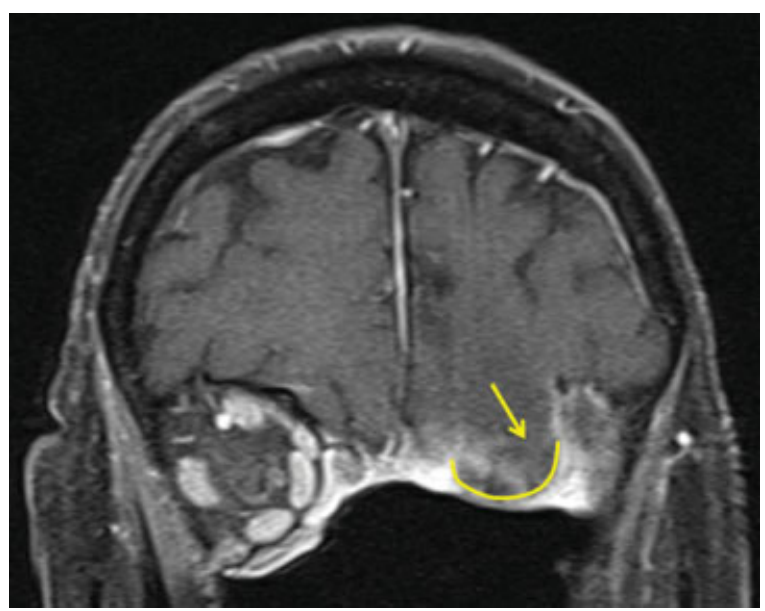

Fig. 2 Magnetic resonance imaging depicting fronto-orbital encephalocele in the region of the leak (yellow arrow).
(Medtronic, Minneapolis, Minnesota, United States) were then placed.

The graft site defect was then repaired. The buccal mucosa was dissected further down to fat, and AlloDerm was used as a biological dressing. This was sutured into place with Vicryl sutures in an interrupted fashion. The total estimated blood loss was $50 \mathrm{~mL}$. Given the likelihood of the patient developing trismus, TheraBite (Atos Medical AB, West Allis, Wisconsin, United States) was given to be used as therapy starting 1 week postoperatively.

\section{Postoperative Course}

The patient was transferred to the neurosurgery intensive care unit and did well in the immediate postoperative period. She had no pneumocephalus, recurrence of meningitis, or donor site morbidity. A lumbar drain (10 mL/hour) and nasal packing remained in place for 5 and 7 days, respectively. The patient was continued on meningitis prophylaxis with vancomycin, aztreonam, and metronidazole. She was discharged home on postoperative day 5. At her 2- and 3-month follow-up visits, the patient reported slight trismus that improved with TheraBite. Nasal endoscopy showed a well-apposed flap with rapid mucosalization and no evidence of flap necrosis. Her Allograft was in place healing well over the donor site. Over the following year, her cancer progressed further including new metastases to the brain and she died 9 months after repair with FAB flap.

\section{Anatomy}

The facial artery branches off the external carotid artery above the lingual artery in the neck and first enters the face deep to the mandible (-Fig. 3). It then loops underneath the body of the mandible at the anterior border of the masseter muscle coursing through the submandibular gland and curving upward to give off branches including the superior and inferior labial, lateral nasal, alar, and angular arteries (-Fig. 4). The facial artery is particularly tortuous as it passes through the face allowing it to experience minimal strain with movements of the mandible. It lies deep to the risorius and zygomaticus major muscles but superficial to the buccinator.

Classically the most common facial artery pattern is thought to terminate with the angular artery at the level of the medial canthus. This represents one of several variants of the facial artery that have been described in the literature based on terminal branching including angular, lateral nasal, alar, superior labial, and inferior labial arteries ( - Fig. 5). ${ }^{14-16}$ The most recent cadaveric study analyzing 201 facial arteries demonstrated that the facial artery pattern terminating in the lateral nasal artery was the most common (48\%) followed by the pattern ending in the angular artery (20\%). ${ }^{17}$ As such, the lateral nasal artery could also be the superior pedicle utilized for the FAB flap, although only the angular artery has been described. Lastly, small perforators including the inferior and anterior buccal branches of the facial artery may be encountered in the inferior and anterosuperior aspects of the buccinator, respectively. ${ }^{9,10}$

The anatomy of the buccinator and facial vein are also key considerations for the FAB flap. The buccinator is a quadrilateral muscle originating at the alveolar processes 


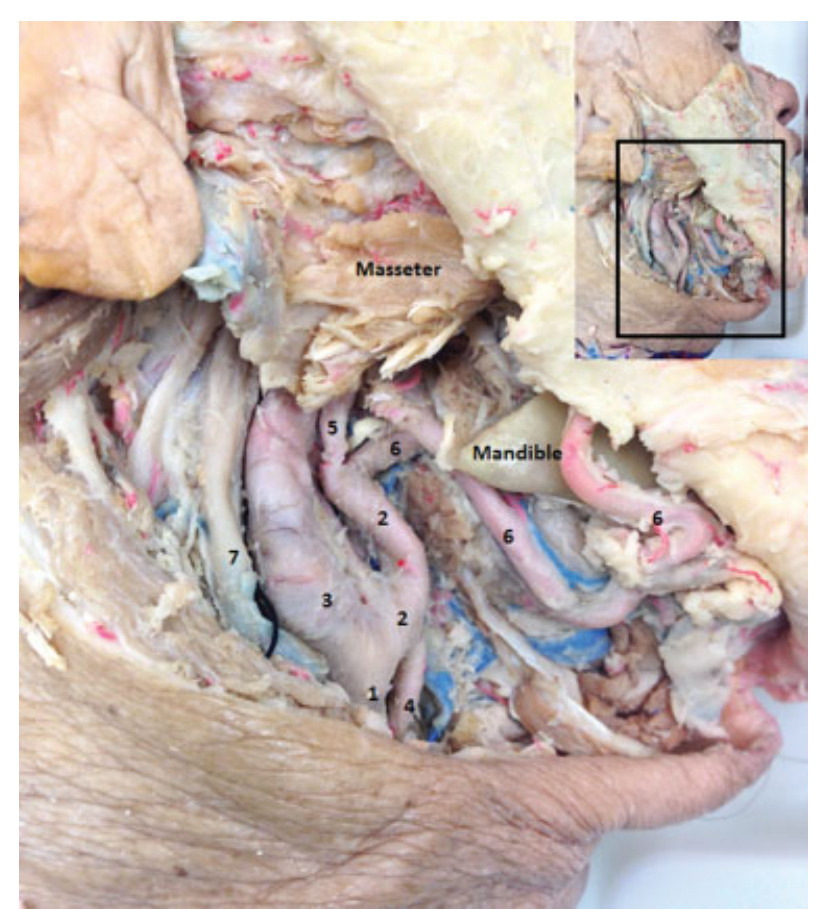

Fig. 3 Vascular anatomy of the neck and lower face with visualization of the facial artery branching from the external carotid artery and coursing underneath the mandible before changing direction. Of note, the mandible was transected in a prior dissection. 1, common carotid artery; 2, external carotid artery; 3 , internal carotid artery; 4 , superior thyroid artery; 5, internal maxillary artery; 6, facial artery; 7, internal jugular vein.

of the maxilla and mandible along the molars. Some of its fibers insert into the buccal mucosa and buccal modiolus; others interlace with fibers of the orbicularis oris. The facial vein is located closely posterior to the facial artery along the body of the mandible but tends to diverge coursing upward. 5,17,18 The facial vein was excluded because the overlying buccal mucosa has been shown to provide sufficient venous drainage. ${ }^{5}$ Variations of the FAB flap have been proposed with and without mucosa. ${ }^{12,13}$ The flaps we raised included mucosa, submucosa, buccinator muscle, and the facial artery.

\section{Harvesting Technique}

Prior to drawing the superior flap boundaries, the parotid duct was palpated, identified, and marked to ensure it was not included in the flap. The flap margins were drawn with a surgical marker beginning with its most anterior border $1 \mathrm{~cm}$ from the oral commissure (-Fig. 6). The superior boundary was then drawn with a dotted line marking the axis of the flap. The flap was drawn as far posterior as the second molar.

The FAB flap was then incised and elevated taking care to include the mucosa, submucosa, and buccinator muscle (-Fig. 7) while dissecting in the plane superficial to the facial artery along the buccal fat pad. Of note, the superior incision of the flap only included mucosa. Previously, two different methods of locating the facial artery have been discussed: a direct distal identification and an anterior dissection tracing the superior labial artery back to the facial artery. ${ }^{11}$ From our

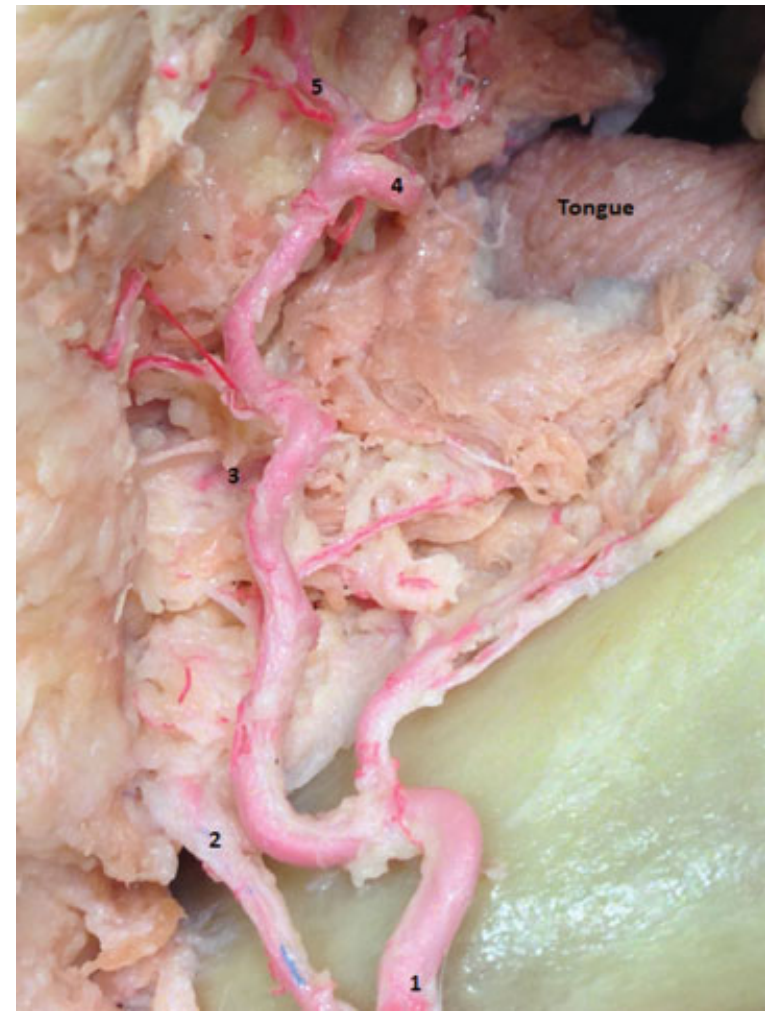

Fig. 4 Facial artery branching in the face. 1, facial artery emergence over mandible; 2 , inferior labial artery; 3 , superior labial artery; 4, lateral nasal artery; 5, angular artery. For orientation, the posterior tongue is visualized because this image was taken following removal of the buccinator and overlying tissue.

anterior incision close to the oral commissure, we traced the superior labial artery back to the facial artery trunk finding this method to be especially useful because the superior labial artery was easily identified in the anterior third of each flap. Care was taken to ensure the facial artery remained attached to the buccinator as the dissection progressed ( $\mathbf{- F i g}$. 8). The branches of the facial artery were not ligated and clipped until the angular artery was located. A full extension of the FAB flap containing the facial artery is shown in - Fig. 9.

The pedicle incisions were then elongated in the direction of the anterior maxilla with a pivot point at the superior gingivobuccal sulcus. A high-speed drill and a periosteal elevator were used to expose the anterior wall of the maxilla ( - Fig. 10), and a generous Caldwell-Luc antrostomy was performed with a superior limit at the level of the infraorbital nerve. Next, utilizing a 0degree endoscope (Stryker), the middle turbinate was medialized and a medial maxillectomy was performed. Care was taken to ensure all bony edges were smoothed in both antrostomies. The flap was then rotated 180 degrees into the Caldwell-Luc antrostomy and transferred into the nasal cavity. Its reach to the anterior cranial fossa, the sella turcica, the clival recess, and the cribriform plate was assessed.

\section{Results}

In all specimens, the facial artery had a near vertical course within the flap and stayed with the middle or posterior third 


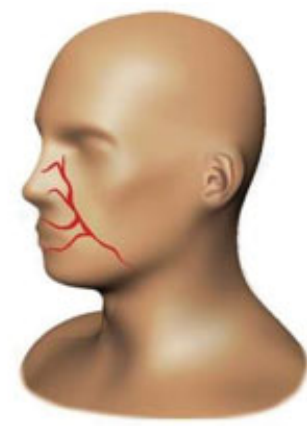

A

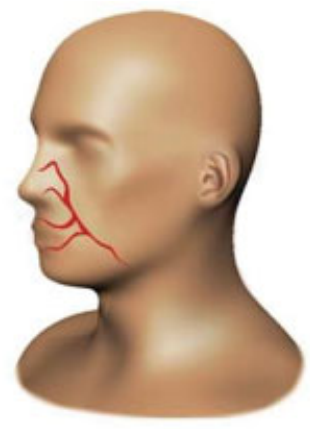

B

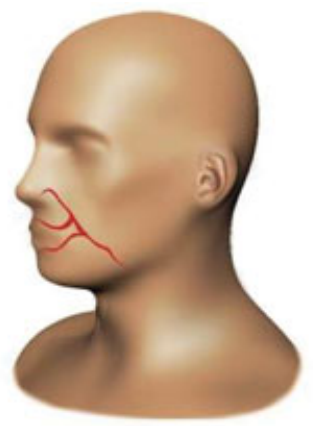

C

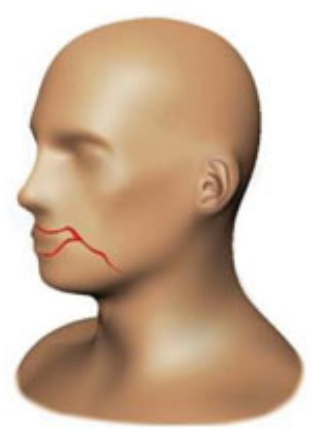

D

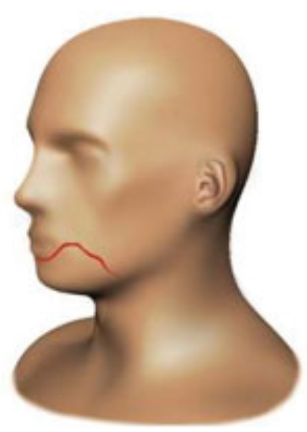

E

Fig. 5 Common facial artery termination patterns. A, angular, B, lateral nasal, C, alar, D, superior labial, E, inferior labial.

of the flap at the level of the inferior and superior incisions. Most of the facial arteries (five of eight) were identified in the middle third of the flap. - Table 1 presents the facial artery course, flap reach, length, and area.

Once transposed into the endonasal cavity, seven of eight flaps covered the sellar/planar regions. In six of eight flaps, complete coverage of the ipsilateral cribriform region was achieved. However, only four of eight flaps were able to cover the contralateral cribriform region, and five of eight flaps crossed the midline. Lastly, no flaps were able to achieve complete coverage of the middle third of the clival region.

\section{Discussion}

Our study reinforces the FAB flap's utility for planar and sellar defect coverage when intranasal pedicled options such as the NSF are unavailable. We particularly recommend the FAB flap for ipsilateral defects because only five of eight of our flaps crossed midline at the level of the anterior cranial fossa. Additionally the flap is not feasible for coverage of the contralateral cribriform plate or the clivus, but coverage of these defects may be possible with an extension involving the mandibular periosteum. ${ }^{13}$ Xie at al demonstrated excellent coverage of the fovea ethmoidalis, the frontal sinus, and the most posterior aspect of the sella turcica with flap extension. ${ }^{13}$ Additionally, the Caldwell-Luc antrostomy should be extended without hesitation as needed to enhance flap reach.
Lastly, we also recommend excluding the facial vein because its inclusion was found to hinder the flap's maximum reach in some cadavers and is not necessary for the flap's venous drainage that is primarily via the buccal plexus. ${ }^{5,13}$

When the flap is first demarcated on the buccal mucosa, it is particularly helpful to divide it into three equal vertical sections extending $1 \mathrm{~cm}$ from the oral commissure to the gingivobuccal sulcus as far back as the second molar. With the knowledge that the facial artery will most likely run in the middle or posterior segments at the level of the mandible, dissection can be directed toward this region, particularly for surgeons who prefer identifying the facial artery distally. Those who prefer to identify the facial artery by following the superior labial artery can find success by dissecting in the anterior third and tracing back to the middle or posterior third of the flap. From our cadaveric FAB flap harvest experience, we recommend the superior labial artery method to locate the facial artery because it avoided the accidental transection of the facial artery before it was intended.

The principles provided in our analysis can be further combined with anatomical data gleaned from prior studies for a more detailed mapping of the dissection. The average facial artery diameter along the lower border of the mandible is $2.6 \mathrm{~mm}$ with a range between 1.7 and $3.6 \mathrm{~mm}$ as previously described. ${ }^{18}$ More superiorly along the nasal alar base, it tapers in size to $1.6 \mathrm{~mm}$ (range: $1.0-2.2 \mathrm{~mm}$ ). ${ }^{18}$ These findings provided by Zhao et $\mathrm{al}^{18}$ highlight a key feature of the FAB flap: the facial artery becomes surprisingly narrow coursing upward but 


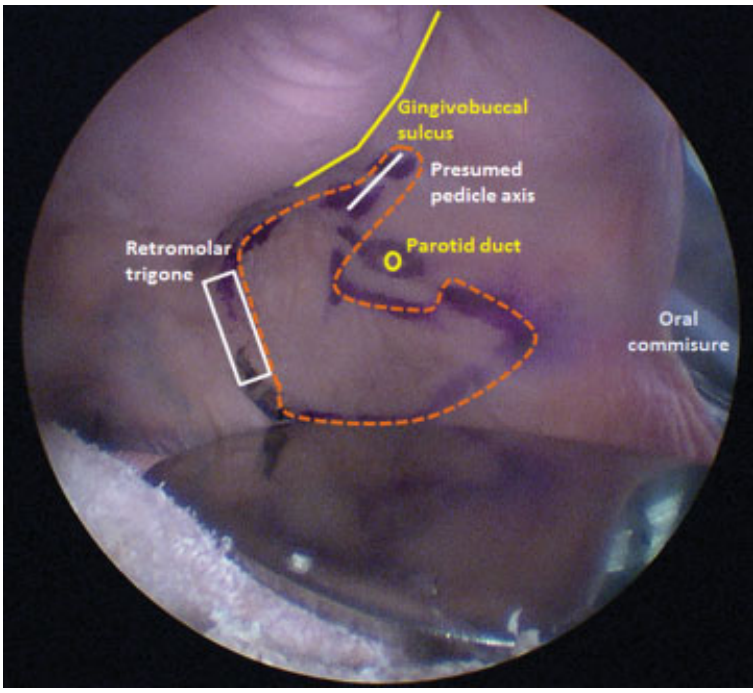

Fig. 6 Flap demarcation and landmarks. The dotted orange line outlines the facial artery buccinator flap.

still provides a sturdy pedicle. Furthermore, the facial artery has been described in relation to several bony landmarks by Dupoirieux et al in utilization of the FAB flap for defects of the hard palate, lower lip, and vestibule. ${ }^{5}$ They measured the facial artery's distance (1) from midline at the superior border of the mandible, (2) from the oral commissure in a plane extending from the oral commissure to the inferior border of pinna, and (3) from the posterior border of the ala nasi in a plane through the ala nasi to the superior border of pinna. ${ }^{5}$ Combining our experience with prior studies yields substantial anatomical background for the harvest and transposition of the FAB flap.

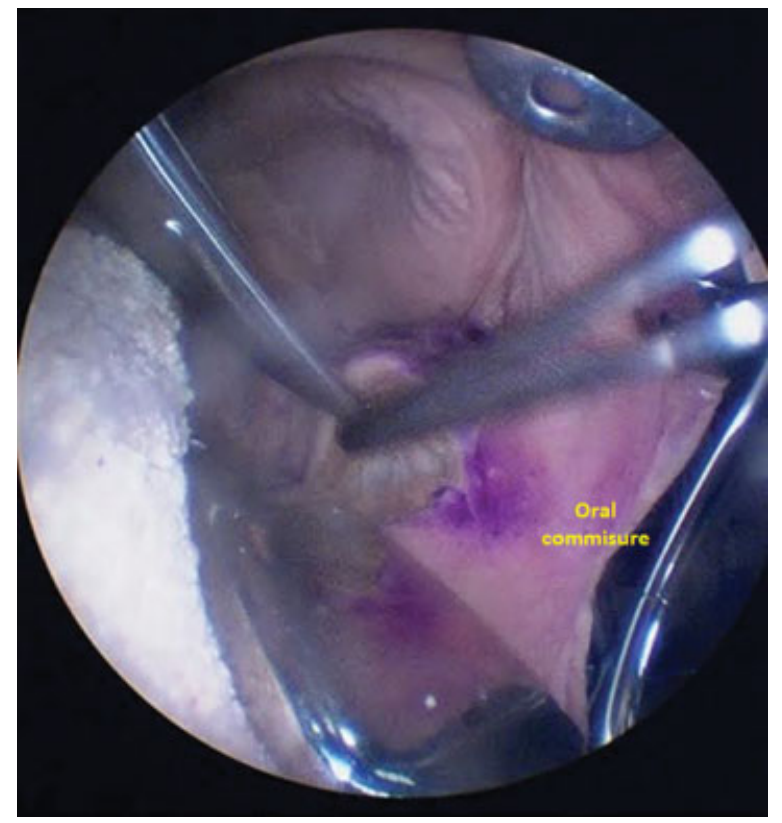

Fig. 7 Flap harvest progressing at the level of the buccinator muscle.

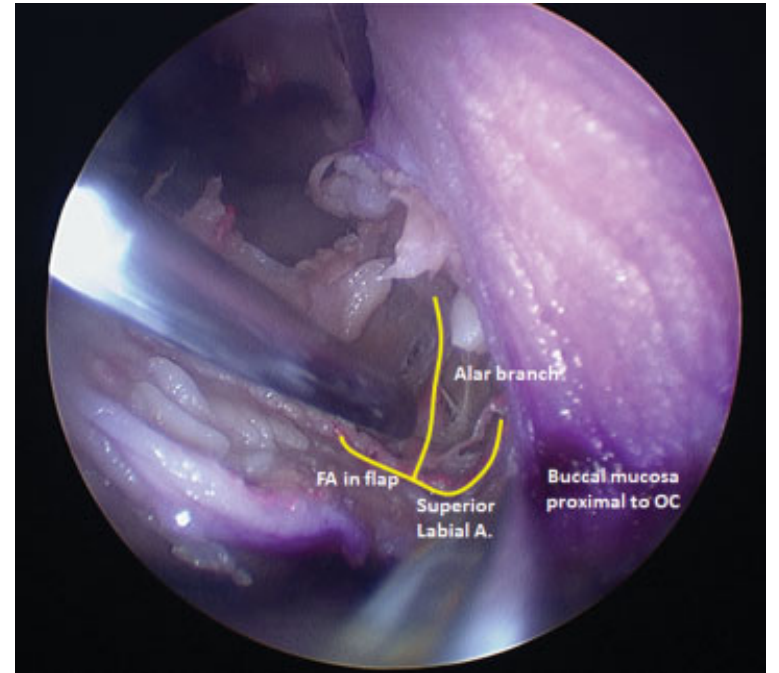

Fig. 8 Visualization of facial artery (FA) in the flap with superior labial and alar branches.

Our patient was initially diagnosed with sinonasal mucosal melanoma eroding the lamina papyracea, cribriform plate, medial wall of the left maxillary sinus, and the nasal septum with dural invasion. Vascular pedicled flaps were the most viable options given their $<5 \%$ rate of postoperative CSF leaks when compared with free mucosal grafts. ${ }^{1,19,20}$ Malignant septal involvement precluded the use of a pedicled NSF. The inferior or middle turbinate flaps were also ruled out due to their described utility in only small defects. ${ }^{1}$ Among extranasal vascular pedicle reconstructive options, a minimally invasive endoscopic

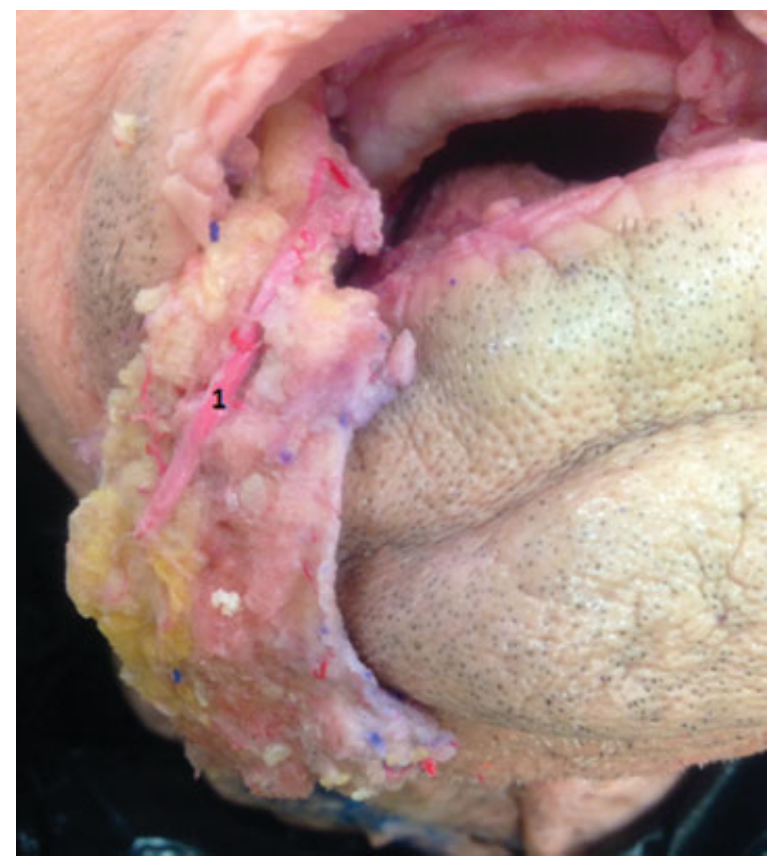

Fig. 9 Facial artery buccinator flap. View of the complete extension of the flap showing the course of the facial artery (1). 


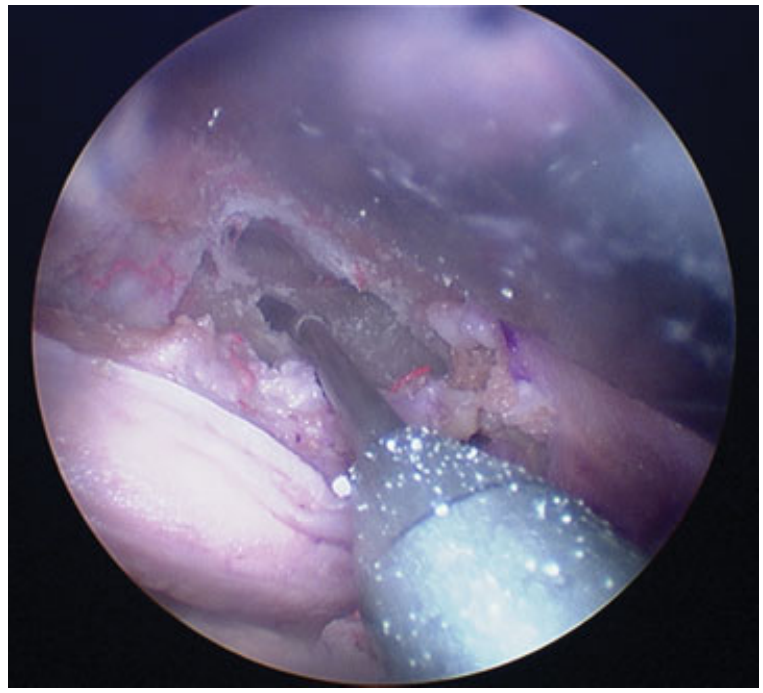

Fig. 10 Extension of the Caldwell-Luc antrostomy with a drill.

pericranial flap was chosen to reconstruct the patient's anterior skull base defect given its versatility, large coverage area, and minimal morbidity ${ }^{1,21}$ as well as our institution's extensive experience with this method. However, the recurrent CSF leak in our patient extended our search for the next most appropriate and effective alternative means of reconstruction. Finally, the FAB flap was considered due to its location outside the radiation field, minimal donor side morbidity, and wide rotational arc., ${ }^{4,11-13}$ Notably, our patient did well postoperatively and only developed mild trismus.

In evaluating the FAB flap for anterior skull base reconstruction, one must also consider its disadvantages and complications. The typical FAB flap in this study was narrow, averaging $3.2 \mathrm{~cm}$ in width, making it a less viable option for wider defects. This limitation is mainly a product of the desire to preserve Stensen duct during flap harvest. However, successful flap harvests have been described in the literature in which the parotid papilla has been included in the flap and a new duct opening has been created by suturing the duct to mucosa before donor site closure. ${ }^{22}$ Additionally, the consequences of an oral cavity resection must be considered. The FAB flap may hinder chewing or prevent denture placement in edentulous patients. ${ }^{11}$ Patients may also require a bite block to prevent them from biting the reconstruction. Operating in the oral cavity can also result in the transfer of oral flora to the skull base with grave consequences. ${ }^{12}$ Previous authors have recommended utilizing chlorhexidine to decrease oral cavity bacteria counts. ${ }^{12}$

Reported complications of the flap include venous congestion, trismus, paresthesias, and persistent epiphoria. ${ }^{11}$ Some studies have demonstrated venous congestion in several patients a few hours following surgery with spontaneous resolution occurring usually within the first 72 hours. ${ }^{23,24}$ Trismus was reported in a total of eight patients in three studies; only one of these patients needed surgery for inner cheek scarring. ${ }^{6,22,25}$ A recent review on FAMM flaps reported partial and total flap necrosis rates of $12.2 \%$ and $2.9 \%$, respectively. ${ }^{11}$ Of note, many patients who experienced partial flap necrosis had oral cavity cancer and had previously undergone chemoradiation. ${ }^{6,22,23}$

Raising the FAB flap is technically challenging for a multitude of reasons. First, the facial artery access is achieved in a manner different from traditional flap vessel access by entering semiblindly from underneath the buccinator muscle. Additionally, the confines of the oral cavity make raising the flap difficult. The use of color Doppler ultrasonography to identify the facial artery has been described, ${ }^{10,18}$ although it may not be available to all surgeons. In light of these challenges, we sought to demarcate important anatomical features that make the FAB flap a more practical pedicled flap option for the surgeon. Because cadaveric embalming methods do not optimally preserve tissue integrity and result in further tissue rigidity/contraction, ${ }^{26}$ flaps raised in cadavers may be significantly shorter than flaps raised in vivo. It should be noted that the specimens used in this study were only

Table 1 Facial artery course, facial artery buccinator flap reach, length, and area measurements

\begin{tabular}{|c|c|c|c|c|c|c|c|c|c|}
\hline \multicolumn{10}{|c|}{ Facial Artery Buccinator Flap Data } \\
\hline No. & Inferior FA & Superior FA & $\begin{array}{l}\text { Anterior } \\
\text { cranial fossa }\end{array}$ & Clival recess & Sella & $\begin{array}{l}\text { Cribriform } \\
\text { plate }\end{array}$ & $\begin{array}{l}\text { Cross } \\
\text { midline? }\end{array}$ & $\begin{array}{l}\text { Flap } \\
\text { length, } \mathrm{cm}^{\mathrm{a}}\end{array}$ & $\begin{array}{l}\text { Flap } \\
\text { area, } \mathrm{cm}^{2 a}\end{array}$ \\
\hline 1 & $\operatorname{mid} 1 / 3$ & mid $1 / 3$ & $\mathrm{~N}$ & $\mathrm{~N}$ & ipsi & $\mathrm{N}$ & $\mathrm{N}$ & 3.8 & 13.1 \\
\hline 2 & post $1 / 3$ & post $1 / 3$ & $\mathrm{Y}$ & $\mathrm{N}$ & $\mathrm{Y}$ & $Y$ & $\mathrm{Y}$ & 5.0 & 14.5 \\
\hline 3 & $\operatorname{mid} 1 / 3$ & mid $1 / 3$ & ipsi & $\mathrm{N}$ & ipsi & ipsi & $\mathrm{N}$ & 4.4 & 11.2 \\
\hline 4 & mid $1 / 3$ & mid $1 / 3$ & $\mathrm{Y}$ & $\mathrm{N}$ & ipsi & ipsi & $\mathrm{Y}$ & 4.5 & 18 \\
\hline 5 & post $1 / 3$ & post $1 / 3$ & $\mathrm{Y}$ & $\mathrm{N}$ & ipsi & $Y$ & $\mathrm{Y}$ & 4.3 & 11.8 \\
\hline 6 & $\operatorname{mid} 1 / 3$ & $\operatorname{mid} 1 / 3$ & $\mathrm{Y}$ & $\mathrm{N}$ & ipsi & $\mathrm{Y}$ & $\mathrm{Y}$ & 5.2 & 19 \\
\hline 7 & post $1 / 3$ & post $1 / 3$ & ipsi & $\mathrm{N}$ & $\mathrm{Y}$ & $\mathrm{N}$ & $\mathrm{N}$ & 4.3 & 11 \\
\hline 8 & mid $1 / 3$ & mid $1 / 3$ & $\mathrm{Y}$ & $\mathrm{N}$ & $Y$ & $Y$ & $Y$ & 5.0 & 18.5 \\
\hline
\end{tabular}

Abbreviations: ant, anterior; FA, facial artery; ipsi, ipsilateral only; mid, middle; N, no; post, posterior; Y, yes.

${ }^{a}$ The flap length and area were measured in situ before cutting the flap and as a result do not account for the additional pedicle length and area that was obtained from flap extension prior to rotation. 
lightly fixed and had tissue characteristics similar to fresh-frozen specimens rather than embalmed specimens. Nonetheless, additional clinical experience is needed to validate the feasibility results highlighted in our cadaveric analysis. In real patients, the flap may have greater reach in the anterior skull base.

\section{Conclusions}

The FAB flap holds great promise in anterior skull base reconstruction. In our study, the flap achieved coverage of the sellar/planar regions and the ipsilateral cribriform plate. However, for contralateral cribriform coverage, the reach of the FAB flap is more limited. Additionally, the flap does not have appropriate reach for larger midclival defects. The FAB flap should be considered as an alternative when more conventional means of coverage are unfeasible. It is technically challenging, and an understanding of the facial artery's course, generally seen in the middle third of the flap, is crucial for its harvest and transposition.

\section{Funding Source}

Zainab Farzal, National Institute of Health/National Institute on Deafness and Other Communication Disorders T32 Training Grant: T32 DC005360. This funding source provided support for Ms. Farzal during the time this study was conducted and had no direct role in its design or conduct.

\section{Acknowledgments}

The authors would like to thank Huda Hashim for her artistic expertise in facial artery illustration.

\section{References}

1 Kim GG, Hang AX, Mitchell CA, Zanation AM. Pedicled extranasal flaps in skull base reconstruction. Adv Otorhinolaryngol 2013;74:71-80

2 Pribaz J, Stephens W, Crespo L, Gifford G. A new intraoral flap: facial artery musculomucosal (FAMM) flap. Plast Reconstr Surg 1992;90(3):421-429

3 Pribaz JJ, Meara JG, Wright S, Smith JD, Stephens W, Breuing KH. Lip and vermilion reconstruction with the facial artery musculomucosal flap. Plast Reconstr Surg 2000;105(3):864-872

4 Ayad T, Kolb F, De Monès E, Mamelle G, Tan HK, Temam S. Le lambeau musculomuqueux de buccinateur pédiculé sur l'artère faciale : technique de prélèvement et indications. Ann Chir Plast Esthet 2008;53(6):487-494

5 Dupoirieux L, Plane L, Gard C, Penneau M. Anatomical basis and results of the facial artery musculomucosal flap for oral reconstruction. Br J Oral Maxillofac Surg 1999;37(1):25-28

6 Ayad T, Kolb F, De Monés E, Mamelle G, Temam S. Reconstruction of floor of mouth defects by the facial artery musculo-mucosal flap following cancer ablation. Head Neck 2008;30(4):437-445
7 Rahpeyma A, Khajehahmadi S, Rezvani HN. Pedicle length in the inferiorly based buccinator myomucosal island flap: a cadaveric study. Int J Oral Maxillofac Surg 2014;43(2):173-176

8 Khan K, Hinckley V, Cassell O, Silva P, Winter S, Potter M. A novel use of the facial artery based buccinator musculo-mucosal island flap for reconstruction of the oropharynx. J Plast Reconstr Aesthet Surg 2013;66(10):1365-1368

9 Van Lierop AC, Fagan JJ. Buccinator myomucosal flap: clinical results and review of anatomy, surgical technique and applications. J Laryngol Otol 2008;122(2):181-187

10 Zhao Z, Li S, Yan Y, et al. New buccinator myomucosal island flap: anatomic study and clinical application. Plast Reconstr Surg 1999; 104(1):55-64

11 Ayad T, Xie L. Facial artery musculomucosal flap in head and neck reconstruction: A systematic review. Head Neck 2014

12 Rivera-Serrano CM, Oliver CL, Sok J, et al. Pedicled facial buccinator (FAB) flap: a new flap for reconstruction of skull base defects. Laryngoscope 2010;120(10):1922-1930

13 Xie L, Lavigne F, Rahal A, Moubayed SP, Ayad T. Facial artery musculomucosal flap for reconstruction of skull base defects: a cadaveric study. Laryngoscope 2013;123(8):1854-1861

14 Koh KS, Kim HJ, Oh CS, Chung IH. Branching patterns and symmetry of the course of the facial artery in Koreans. Int J Oral Maxillofac Surg 2003;32(4):414-418

15 Niranjan NS. An anatomical study of the facial artery. Ann Plast Surg 1988;21(1):14-22

16 Mitz V, Ricbourg B, Lassau JP. Les branches faciales de l'artère faciale chez l'adulte. Typologie, variations et territoires cutanés respectifs. Ann Chir Plast 1973;18(4):339-350

17 Lohn JW, Penn JW, Norton J, Butler PE. The course and variation of the facial artery and vein: implications for facial transplantation and facial surgery. Ann Plast Surg 2011;67(2): 184-188

18 Zhao Z, Li S, Xu J, et al. Color Doppler flow imaging of the facial artery and vein. Plast Reconstr Surg 2000;106(6):1249-1253

19 Gardner PA, Kassam AB, Thomas A, et al. Endoscopic endonasal resection of anterior cranial base meningiomas. Neurosurgery 2008;63(1):36-52; discussion 52-54

20 Zanation AM, Thorp BD, Parmar P, Harvey RJ. Reconstructive options for endoscopic skull base surgery. Otolaryngol Clin North Am 2011;44(5):1201-1222

21 Zanation AM, Snyderman CH, Carrau RL, Kassam AB, Gardner PA, Prevedello DM. Minimally invasive endoscopic pericranial flap: a new method for endonasal skull base reconstruction. Laryngoscope 2009;119(1):13-18

22 O'Leary P, Bundgaard T. Good results in patients with defects after intraoral tumour excision using facial artery musculo-mucosal flap. Dan Med Bull 2011;58(5):A4264

23 Massarelli O, Baj A, Gobbi R, et al. Cheek mucosa: a versatile donor site of myomucosal flaps. Technical and functional considerations. Head Neck 2013;35(1):109-117

24 Joshi A, Rajendraprasad JS, Shetty K. Reconstruction of intraoral defects using facial artery musculomucosal flap. Br J Plast Surg 2005;58(8):1061-1066

25 Wolber A, Mallet Y, Avalos N, Martinot-Duquennoy V, Lefebvre JL. Etude de la sensibilité du lambeau de FAMM : à propos de 15 cas. Ann Chir Plast Esthet 2009;54(2):120-125

26 Eisma R, Wilkinson T. From "silent teachers" to models. PLoS Biol 2014;12(10):e1001971 